\title{
An Investigation of Relationship between Self-Efficacy and Academic Achievement among Second Year Robe College Students
}

\author{
Kefyalew Kebebe Ayane ${ }^{1}$ (MA) \\ kefyalewk2012@gmail.com \\ Madda Walabu University, College of Education and Behavioural Studies, \\ Department of Psychology, Bale Robe, Ethiopia
}

\begin{abstract}
The major purpose of this study was to investigate the relationships between selfefficacy and students academic achievements in Robe College of Teachers Education. In order to attain the objectives and basic research of the current study, a descriptive survey research design was employed. The data were collected in self-report questionnaire developed from (Yazachew, 2005 and Shkullaku, 2013, self-efficacy scale). Regarding academic achievement, students' CGPAs were collected from office of the registrar. Among 723 target population, 252 participants were selected based on stratified random sampling. Analysis and findings was based on the responses of 241 respondents. With respect to analysis, descriptive statistics such as frequency, mean, range, standard deviation and correlation coefficient were employed. Moreover, t-test was also used to investigate gender difference. The current study revealed that, significant symptoms of low self-efficacy was observed; the study identified that more than half of the students were under low self-efficacy, the finding also showed that, students' with low self-efficacy were scored low CGPA and students with high self-efficacy scored high CGPA. With regard to the relation, self-efficacy was significantly and positively correlated with academic achievement (.54). Moreover, the recent study indicated that there was significant gender differences in self-efficacy $(t=4.26, p<0.05)$, which was indicated the presence of significant differences existed between male and female students of the college and, in favouring male students were significantly better than female students and also female students were more affected than male students by self-efficacy. Finally, on the bases of the findings possible recommendations like; providing preliminary training for candidates, Oromia Regional Educational Bureau and College should have to recruiting high academic achievers, establishing guidance \& counselling services, providing on-the-job trainings on continuous bases on life skills, and by giving due attention for gender unit and low achievers were forwarded.
\end{abstract}

Key words: Academic achievements, Self-efficacy

\section{Introduction}

Self-efficacy is a belief of students' in their ability to internalize new skills and tasks, often in an academic area. Moreover, self-efficacy is a belief of one's capabilities to organize and execute the courses of action required to produce given attainments (Bandura, 1997; Elias \& Loomis, 2000; Feltz, Short \& Sullivan, 2007; Koseoglu, 2015). Self-efficacy is also beliefs that influence a task of choice, effort, persistence and achievement (Schunk, 1995; Bandura, 1997). Self-efficacy is related to belief of everyone in which one has to assess his or her abilities to perform a given task successfully. This concept has a high influence on the link to the task, the perseverance to accomplish the same task and as well as the level of effort (Goulao, 2014; Koseoglu, 2015).

This indicates that self-efficacy is a measure of control over individual's thoughts, feelings and actions. In addition self-efficacy is beliefs that individuals grasp about their abilities and outcome of their efforts which affect ways they will behave. Additionally, self-efficacy is how 
confident people believe they are, or how much control believes they have in their ability to reach a goal or accomplish a task (Goulao, 2014; Usta, 2017). This sense of control is fundamental importance in everyday life because, theoretically, people who lack the control in their lives to produce a desired effect are individuals who will have little incentive to put forth any effort towards achievement.

Academic achievement is the effect of education students grasp at university or college in class room, library and fieldwork. In general, academic achievement is defined as a student's academic performance in elementary or junior, high school and college or University (Chen and Thuen, 2007; Kpolovie, 2014; Ching, Wang \& Liu, 2020). Thuen (2007) and Kpolovie (2014) explored that students' ability to identify with positive academic qualities and to establish educational goals related to high scholastic achievement but many students are unable to identify with the qualities associated with successful academic achievement due to low academic self-efficacy. Academic performance indicates how well a student is achieving his or her activities and lessons. The most well-known indicator of academic achievement is grade of the students' they score in a classes and overall performance.

As soon as these students became aware of their goals/intentions they proceed to look for results they should have to perform. Furthermore, they start to perceive the products of education as an input for their development of skills, knowledge, and their whole behavioral changes. Regarding this, after the students adjusted to the college situations, develop and practice their education to achieve their academic knowledge, skills and attitudes (Borich, 1988; Sadler \& Sadler, 1999; Durlak \& Weissberg, 2001; Lilian. 2012; Goulao, 2014; Usta, 2017). This indicates that students have to adjust to their academic achievement expecting responsibility for these tasks and accomplish it in their daily activities and enhance a new life again; they attempt to score good result for the accomplishment and scores good results in the college to successes and adjust their life for the future.

In the academic context, self-efficacy is students' belief in their personal efficacy to control their own educational processes, outcomes and to become effective in a course they are learning likely has a great influence on their academic achievement.

On the opposing, low self-efficacy brings academic failure which causes a high dismissal of the learners from their education. There are various problems that hinder learners in order not to continue their learning. Among these, the most challenging problem is psychological problems like low self-efficacy (Borich, 1988; Ysseldyke \& Algozzine, 1995; Sadler \& Sadler, 1999; Lampard, 2007). Moreover, inability to cope with low self-efficacy in academic achievement may be lead students to low academic self-efficacy (Lampard, 2007; Akomolafe, 2013).

There are several studies that show a correlation between the level of self-efficacy and academic performance. In general, most researchers have concluded that many studies have consistently demonstrated that academic self-efficacy beliefs are strong determinants of academic accomplishments (Ferla \& Valcke, 2009; Yazachew, 2012; Akomolafe, 2013; Koseoglu, 2015; Yokoyama, 2019).

On the contrary, some researchers indicated that the way learners make use of the learning strategies and motivated, increases their academic achievements but not self-efficacy. (Jeffreys, 1998; Ferla, Martin \& Cai, 2009) have found that the perceived self-efficacy could not decrease academic achievement in a direct. Moreover, Yusuf (2011) and Oyuga, Raburu \& Aloka (2019) found that self-efficacy has low or weak impacts on academic achievements. From this one can infer that self-efficacy has not positive relationship or weak positive relationship and not highly influences academic achievements. Jeffreys (1998), Yusuf (2011) and Oyuga, Raburu \& Aloka (2019) defined that the more challenging the goals are the more motivating students. So this indicates that low self-efficacy does not affect students` academic achievements and self-efficacy has not a positive relationship with academic achievements. As a result this study tries to examine this difference. 
Accordingly, College of Teachers` Education is responsible for ensuring the candidates knowledge, skill, and their professional right. In terms of this teachers`college has mandates to make the learners knowledgeable, skillful and professional (Borich, 1988; Federal Educational Policy, 1999; Charter of Oromia Regional State, 2013; Talluri, 2018). However, concerning this issue especially in College of Teachers`Education in Oromia regional state, there has not been detail investigation on low self-efficacy of learners` lives who would be teachers. As a result higher institutions specifically College of Teachers`Education are affected by psychological problems on their education (Yazachew, 2012).

Moreover, students who scored "D" or "F" become under survival and become warned or dismissed from the college. The same situations were observed in Robe College in relation to their achievements. Each year below pass achievers were abundant and stopped their education. For instance, in 2016 the number of dismissals, warned and border achievers were 280/950; in 2017, 253/700; in 2018, 235/600 and in 2019, 223/550 candidates. From these the numbers of dismissals were 263; warned and border achievers were 728 . These require immediate solution from the institution to run fast with the quality of education programmed as the country and it intended to examine the Relationship between Self-efficacy and Academic Achievement.

\subsection{Objectives of the Study}

The study was anticipated to achieve the following objectives:

$\checkmark \quad$ To examines Self-efficacy among college students.

$\checkmark \quad$ To explores relationship between self-efficacy and academic achievements among college students.

$\checkmark \quad$ To identify gender differences in academic self-efficacy among college students.

\subsection{Research Questions}

The research was intended to answer the following research questions.

$>$ What is the status of self-efficacy among college students?

$>$ What are the relationships between self-efficacy and academic achievements among college students?

$>$ Is there a gender difference in academic self-efficacy among college students?

\section{Research Methods}

The following procedure was used to carry out the study:

\subsubsection{Research Design}

To investigate the relationship between self-efficacy and academic achievement, the researcher employed quantitative method. To overcome this study a descriptive survey design was employed. Descriptive survey helps to figure out what exists at present by determining nature and existing situation of the issues under the study in quantitative data collected through questionnaire in the study area (Kothari, 2004).

\subsubsection{Population and Sampling}

The target population of the study conducted was: 2018/2019 second year regular students, total number of 723 of four streams (Natural Science \& math, Social Science, Language, and Aesthetics and physical education). From these target population, the number of sample respondents was determined using Krejcie and Morgan (1970) suggestion. Using the above 
scholars' suggestion among 723 target population 252 (34.85\%) students were identified as sample size. However, analysis and findings of the current study was based on the 241 respondents to the questionnaire. The students were selected using stratified random sampling technique to fill out the questionnaire. The detailed descriptions were illustrated in table 1.

Table 1: Population and the Sample by Stream

\begin{tabular}{|l|l|l|l|l|l|l|l|l|l|l|}
\hline \multirow{2}{*}{ No } & \multirow{2}{*}{ Stream } & \multicolumn{3}{|c|}{ Population } & \multicolumn{3}{|l|}{ Sample } & \multicolumn{2}{l|}{$\begin{array}{l}\text { Correctly } \\
\text { Responded }\end{array}$} \\
\cline { 3 - 12 } & M & F & Total & M & F & Total & $\%$ & Count & $\%$ \\
\hline 1 & $\begin{array}{l}\text { Natural science } \\
\text { and mathematics }\end{array}$ & 197 & 297 & 494 & 65 & 103 & 168 & 34.01 & 161 & 95.83 \\
\hline 2 & Social Science & 15 & 33 & 48 & 6 & 15 & 21 & 43.75 & 20 & 95.24 \\
\hline 3 & Language & 26 & 75 & 101 & 10 & 25 & 35 & 34.65 & 33 & 94.29 \\
\hline 4 & $\begin{array}{l}\text { Aesthetics and } \\
\text { physic. education }\end{array}$ & 29 & 51 & 80 & 11 & 17 & 28 & 35.00 & 27 & 96.43 \\
\hline \multicolumn{2}{|l|}{ Total } & 267 & 456 & $\mathbf{7 2 3}$ & 92 & 160 & 252 & 34.85 & 241 & 95.63 \\
\hline
\end{tabular}

\subsubsection{Data Collection Instruments}

In this study, the main instrument used in the study was questionnaire.

Questionnaire: In this study questionnaire was used. This questionnaire was on academic self-efficacy which was prepared for students self-report to measure their academic performance (CGPA) using four point Likert Scales.

Academic Self-efficacy: symptoms of items were adopted from (Yazachew, 2005; Shkullaku, 2013). It consisted 15 items.

The average scores of second year students' Cumulative Grade Point Average (CGPA) of consecutives three semesters for each student were collected from registrar office of the college involved in the study to measure academic achievement.

\subsubsection{Data Analysis Procedure}

Quantitative data obtained through questionnaire was checked and organized with respect to the objectives and basic research questions. Analysis was made using descriptive statistics (Frequency, percentage, mean, range and standard deviation) and Pearson correlation was also used to measure the relationships between students`academic performances and self-efficacy. It also used to examine difference between male and female students` responses for the selfefficacy. Moreover, independent t-test was also employed to test the significance level of differences observed on self-efficacy and gender differences in particular. In this regard the SPSS v-20 was used to facilitate the organization and facilitation of analysis and interpretation of the data using tables and charts.

\section{Conceptual Frameworks of the Study}

The occurrence of self-efficacy that is characterizes students` potential consequences and affects students` academic achievements in relation to Cumulative Grade Points Average (CGPA) were discussed. Under this the meaning of self-efficacy, academic achievement and relationships between the two variables were explained depending on different scholars. 


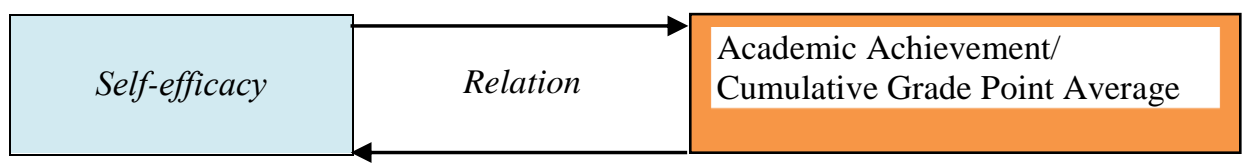

Figure 1: A Model Developed from (Yazachew, 2005; Shkullaku, 2013)

Self-efficacy (Independent variable): Self-efficacy refers to an individuals` belief that they can effectively accomplish at a designated level on an academic task or attain an academic objectives (Bandura, 1997; Feltz, Short \& Sullivan, 2007). In the present study, selfefficacy is further advanced to academic self-efficacy. Academic self-efficacy denotes to students belief in that they can successfully achieve designed academic activity on specific academic goal. In the present research, self-efficacy is further defined as respondents' academic self-efficacy in dealing and scoring with all courses in the past three semesters.

Academic achievement (Dependent variable): Based on previous literature, there were numerous definitions of academic achievement. In general, academic achievement was defined as a student's academic performance in school (Chen, 2007; Kpolovie, 2014; Ching, Wang \& Liu, 2020). In this study, academic achievement mainly refers to the respondents' actual grade in the three consecutives semesters in all courses, their confidence, effort and emotion in dealing with all courses and achieves.

The Relationship between Self-efficacy and Academic Achievement: Many researchers have attempted to relate self-efficacy to different educational, social, and psychological factors such as the strategies of learning (Ferla, Valcke \& Cai, 2009; Yokoyama, 2019), motivational constructs such as persistence and goals setting (Yazachew and Sahravard \& Hassen, 2012), which affect constructs of knowledge. This infers that students with higher levels of self-efficacy more motivated to learn and higher successful in academic achievement than their colleagues who are low in academic self-efficacy.

Research examined the relationship between self-efficacy and academic achievement of students at different levels of education, with the exception of a few studies (Ferla, Valcke \& Cai, 2009), students with higher levels of academic self-efficacy have significantly higher academic performance when compared to their peers who are low in academic self-efficacy. If students have strong beliefs in their academic abilities to perform well, they will have higher academic achievement than their friends' with low beliefs in their abilities to perform well academically. Similarly, Self-efficacy is positively and significantly predicted academic performance (Akomolafe; Lilian, 2012; Talluri, 2018; Yokoyama, 2019).

On the other hand, a few researchers indicated that the way learners make use of the learning strategies and motivated increases their academic achievements but not self-efficacy. (Jeffreys, 1998; Ferla, Valcke \& Cai, 2009) have found that the perceived self-efficacy could not decrease academic achievement in a directly. Moreover, Yusuf (2011) and Oyuga, Raburu \& Aloka (2019) found that self-efficacy has low influences on academic achievements. Which are contradicts with many scholars. As a result this study tries to investigate the differences. 


\section{Data Analysis and Discussion of the Results}

The collected data were organized, tabulated and analyzed by using frequency, percentage, mean, range, standard deviation, correlation, and t-test to achieve the objectives and research questions. Analysis and findings of the current study was based on the responses of 241 respondents to the questionnaire. The results were interpreted and discussed. This part also discussed about background information of the respondents; which includes about sex, age, stream, and academic achievement (CGPA) of the students.

\subsection{Respondents' Background Information}

Table 2: Information Related to Background of the Respondents in terms of Sex, Age, and Streams

\begin{tabular}{c|ccc}
\hline \multirow{3}{*}{ Academic Streams } & Count & $\%$ \\
& Natural Science \& Mathematics & 161 & 66.80 \\
& Social Science & 20 & 8.30 \\
& Language Stream & 33 & 13.69 \\
& Aesthetics \& Physical Education & 27 & 11.20 \\
& Total & 241 & 100 \\
\hline \multirow{3}{*}{ Sex } & Male & 88 & 36.51 \\
& Female & 153 & 63.49 \\
& Total & 241 & 100 \\
\hline \multirow{3}{*}{ Age } & $18-20$ years & 180 & 74.69 \\
& $21-23$ years & 43 & 17.84 \\
& $24-26$ years & 13 & 5.39 \\
& Above 27 years & 5 & 2.07 \\
& Total & 241 & 100 \\
\hline
\end{tabular}

Data from table 2indicated, the majority of the respondents were female. They account for $63.49 \%$ of all respondents; and the numbers of male respondents were $36.51 \%$. The presences of high percent of female respondents were observed in this study. This may be associated with the quota allocated by the government for female candidates during the selection of college entrant. In relation to this, a guideline for selection of diploma level teachers for preservice training program allowed large number of female candidates (more than $60 \%$ ) to join teacher education colleges for pre-service training in Oromia (Oromia Education Bureau, August 2017/8).

Concerning the age of the respondents, almost three-fourth of them (74.69\%) was found between 18-20 years age group. Moreover, the respondent with 21-23 years old accounts $17.84 \%$. There were also few respondents $(7.46 \%)$ with highest age (above 24 years old).

In terms of academic stream; among the four streams currently students were attending their teachers' education courses; the majority of the students $(66.80 \%)$ were from Natural Science and Mathematics stream. The remaining students were almost equally represented from the three streams; in that, 13.69\% from Language, $11.20 \%$ from Aesthetics and Physical Education, and $8.30 \%$ from Social Science stream. Even though, the number of respondents from these streams seems small; in comparison to population of the respondents; they rationally represented each stream to respond the questionnaire. Currently about $70 \%$ of the 
students were attending their Education in Natural Science and Mathematics stream of the college.

In general the majority of the respondents were female with 18-20 years old, and from natural science and mathematics stream of the college. So this indicated that majority of second year students were female students.

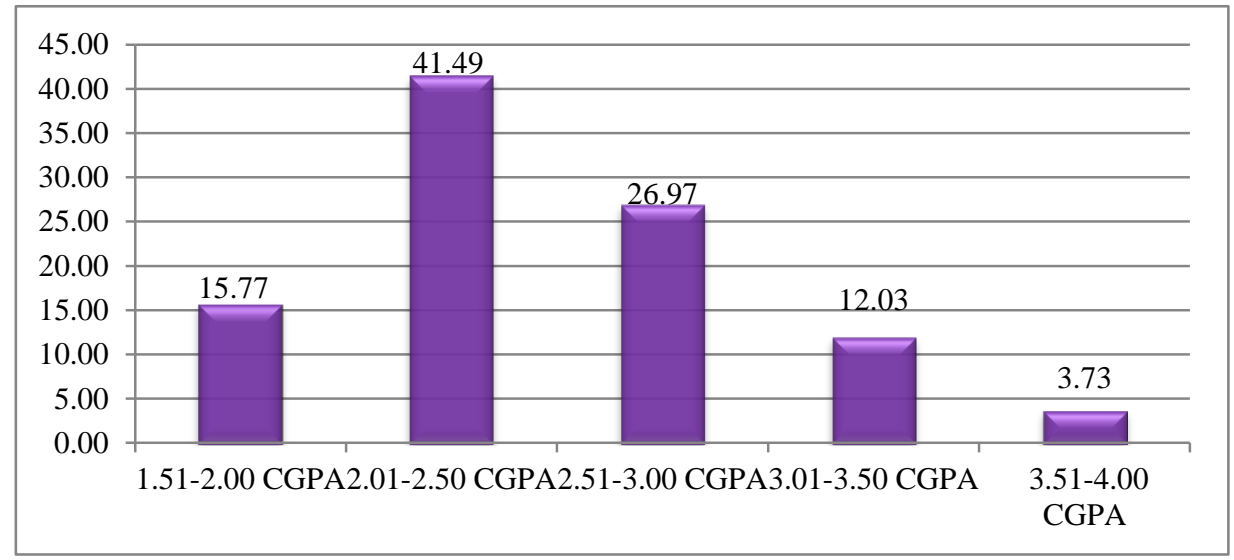

Figure 2: Number of Respondents' in terms of their Academic Achievements (CGPA)

Figure 2 indicated that; academic achievements of the respondents were illustrated. The respondents were given alternatives to respond their CGPA of the previous semesters (during 2017/18 academic year and first semester of 2018/19 academic years).

Accordingly, the data in figure 2 shows, majority of the students (41.49\%) were achieved 2.01 to 2.50 CGPA during the past semesters of their study. Moreover, 20.75\% had achieved 2.51 to 3.00 CGPA; and $15.77 \%$ of them had achieved 3.01 to 3.50 CGPA. On the other hand, the number of students with highest CGPA (above 3.50) and lowest CGPA (below 2.00) account $6.22 \%$ and $15.77 \%$, respectively.

Totally, the data illustrated in the figure shows that more than half of the students' $(57.26 \%)$ academic achievement was found below 2.50 CGPA. Among these, $15.77 \%$ of the students' were with lowest CGPA (below 2.00). On the contrary; students who achieved highest academic performance, that is, above 3.50 CGPA account only for $6.22 \%$ of all students participated as sample respondents in this study.

In this regard, the data obtained from registrar office of the college shows relatively similar percentages of the number of students in each category of CGPA illustrated in figure one. According to the data of the registrar office, $17.56 \%$ of the students`CGPA was below $2.00 ; 43.15 \%$ of them had achieved 2.01 to $2.50 ; 24.76 \%$ of them were registered 2.51 to 3.00; $11.34 \%$ of them were obtained 3.01 to 3.50 ; and $3.18 \%$ of them had achieved above 3.50 CGPA.

Thus, the data related to academic achievements of students, reported by respondents and illustrated in figure one was synonymous with the overall data of the registrar office of the college about students`academic achievements (CGPA) during previous semesters. The above finding indicated that, many students may expose to low self-efficacy. 


\subsubsection{Status of Self-efficacy among the Students}

As academic self- efficacy is referred as a student's view of his/her academic ability when compared with other students. Respondents were asked to rate some items related to selfefficacy using four point scales questions (1= Never $2=$ Sometimes $3=$ Most of the times 4= Always). Their responses were organized and illustrated in the following tables and figures.

Table 3: Respondents Responses on Items of Self-Efficacy ( $\mathrm{N}=241)$

\begin{tabular}{|l|l|c|c|c|}
\hline $\mathrm{N}^{\mathrm{o}}$ & Items & Mean & SD & Ranks \\
\hline 1 & I ask questions in class & 2.32 & 0.737 & 11 \\
\hline 2 & I can do well in classroom discussion. & 2.50 & 0.949 & 9 \\
\hline 3 & I communicate with my colleagues and other students well & 2.04 & 0.957 & 15 \\
\hline 4 & $\begin{array}{l}\text { I study very hard to perform well on tests, and } \\
\text { examinations }\end{array}$ & 2.56 & 0.961 & 7 \\
\hline 5 & I appropriately organized my studies and write papers & 2.56 & 0.879 & 6 \\
\hline 6 & I keep up well with required readings & 2.59 & 0.837 & 5 \\
\hline 7 & I understand my course materials very well & 2.49 & 1.084 & 10 \\
\hline 8 & If I encountered a problem; I ask my teachers & 2.19 & 0.951 & 13 \\
\hline 9 & I take class notes properly & 2.67 & 1.007 & 4 \\
\hline 10 & I do well an assignments, test, and exams & 2.72 & 0.959 & 1 \\
\hline 11 & I am improving my achievements from time to time. & 2.68 & 0.905 & 3 \\
\hline 12 & I do academic activities very well in college & 2.51 & 0.996 & 8 \\
\hline 13 & I get the grades I want & 2.25 & 0.924 & 12 \\
\hline 14 & I understand well what teachers teach in the class & 2.70 & 0.977 & 2 \\
\hline 15 & I meet my parents expectation of my grades & 0.980 & 14 \\
\hline & All items & & \\
\hline
\end{tabular}

Based on table 3, almost all items were responded by all students. However, the following five items were identified by students as the top-five items of self-efficacy: I do well an assignments, test, and exams (2.72\%); I understand well what teachers teach in the class (2.70\%); I am improving my achievements from time to time (2.68\%); I take class notes properly $(2.67 \%)$; and I keep up well with required readings $(2.59 \%)$. On the other hand; items like I communicate with my colleagues and other students well (2.04\%); I meet my parents expectation of my grades (2.14); If I encountered a problem; I ask my teachers (2.19\%); I get the grades I want (2.25\%); and I ask questions in class $(2.32 \%)$ were reported by students as they are the five least items of self-efficacy.

The result indicated that self-efficacy, $42.46 \%$ of students with lower CGPA were reported "Never. On the contrary the majority of students (46.67\%) with highest grade (above 3.51) had reported "Always".

The overall result of students' positive responses for self-efficacy items was increased with a raise of students' academic achievements and the overall agreements of students for items 
related to self-efficacy were found at 2.46 mean score out of four point scale. Research works of other researchers also confirm this and similar with study conducted by (Yusuf, 1998; Yazachew, 2012).

Generally result of students' positive responses for self-efficacy items was increased with an increment of students' academic achievements. The result of this study was also the same with similar study done by (Ferla, Valcke \& Cai, 2009; Akomolafe, 2013; Talluri, 2018). Low achievers responded as they had low self-efficacy. More than half of the respondents in Robe College of Teachers Education were under low self-efficacy. The result indicated that the college was not giving training for students on life skills.

In summary the results of self-efficacy responses of the students illustrated in table 4 indicates that, the presence of efforts among students at college level to get better performances in their academic achievements. However, they did not give proper attention for items of self-efficacy i.e. self-beliefs that focuses on their academic performance as well as their relationship with colleagues, students, parents, and their teachers.

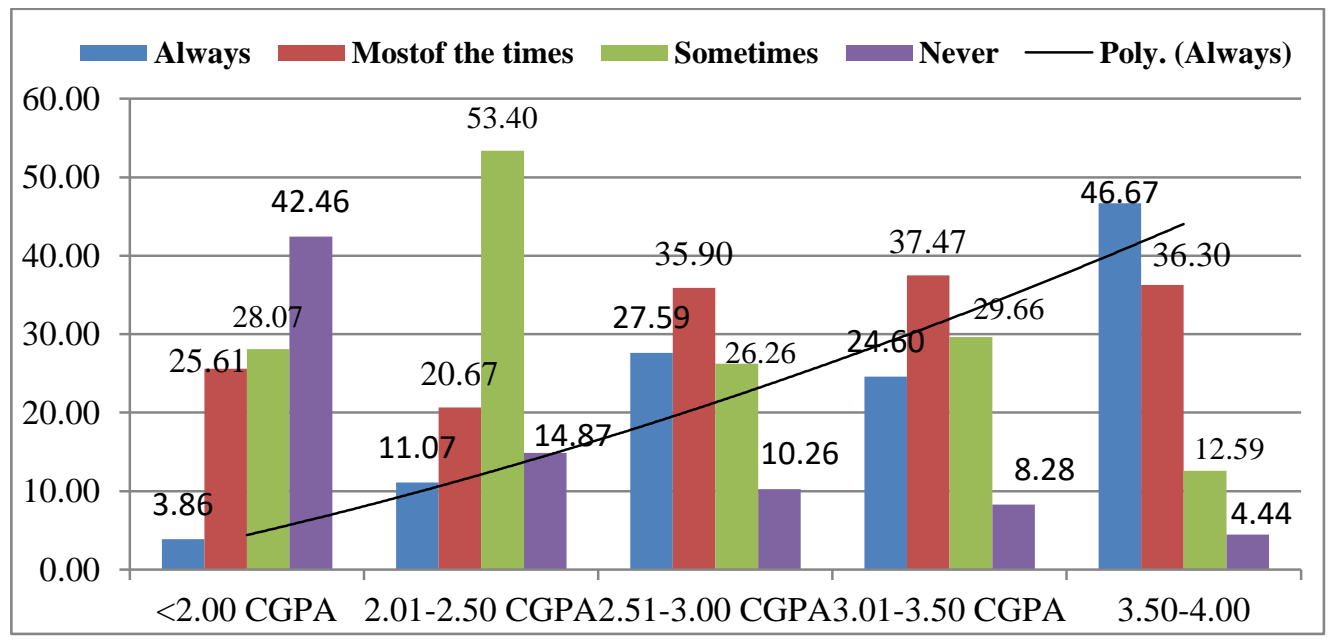

Figure 3: Students' Self-efficacy Reports and Academic Achievements (CGPA)

The comparison made between the agreement level of the students for all item of selfefficacy and their respective CGPA (as illustrated in figure 3) showed the occurrences of certain discrepancy among students' responses.

The data of figure 3 shows that $42.46 \%$ of students with lower CGPA were reported "Never". On the contrary the majority of students (46.67\%) with highest grade (above 3.50) had reported "Always". On the other hands, $27.59 \%$ of the students with 2.51 to 3.00 CGPA were responded "Always" than students with 3.01 to 3.50 CGPA (24.60\%) about their selfefficacy level. However, the data in figures 3 show that, the overall result of students' positive responses for self-efficacy items was increased with a raise of students' academic achievements. 


\subsubsection{Relationship between Self-efficacy and Academic Achievements}

One of the objectives of this study was to examine the relationship between self-efficacy and academic achievements. Accordingly, as illustrated in table 4; the relationship between academic achievements of the students' and self-efficacy were examined as follows:

Table 4: Summary of Descriptive Statistics: Self efficacy and Students’ Academic Performances $(\mathrm{N}=241)$

\begin{tabular}{|c|c|c|c|c|c|c|c|}
\hline \multirow{3}{*}{\multicolumn{2}{|c|}{$\begin{array}{l}\text { Self-efficacy and Students' } \\
\text { Academic Achievements }\end{array}$}} & \multirow[b]{3}{*}{$\mathrm{N}$} & \multirow[b]{3}{*}{ Mean } & \multirow{3}{*}{$\begin{array}{c}\text { Std. } \\
\text { Deviation }\end{array}$} & \multirow{3}{*}{$\begin{array}{l}\text { Std. } \\
\text { Error }\end{array}$} & \multicolumn{2}{|c|}{$\begin{array}{l}95 \% \text { Confidence } \\
\text { Interval for Mean }\end{array}$} \\
\hline & & & & & & Lower & Upper \\
\hline & & & & & & Bound & Bound \\
\hline \multirow{6}{*}{$\begin{array}{l}\text { Self- } \\
\text { efficacy }\end{array}$} & 1.51-2.00 CGPA & 38 & 1.909 & .5226 & .085 & 1.737 & 2.081 \\
\hline & 2.01-2.50 CGPA & 100 & 2.279 & .5651 & .057 & 2.167 & 2.391 \\
\hline & 2.51-3.00 CGPA & 65 & 2.808 & .4931 & .061 & 2.686 & 2.930 \\
\hline & 3.01-3.50 CGPA & 29 & 2.784 & .5391 & .100 & 2.579 & 2.989 \\
\hline & 3.51-4.00 CGPA & 9 & 3.252 & .1694 & .057 & 3.122 & 3.382 \\
\hline & Total & 241 & 2.461 & .6358 & .041 & 2.380 & 2.541 \\
\hline
\end{tabular}

The data in table 4 illustrated, descriptive summary of self-efficacy and academic performances (CGPA) of the students responded by sample respondents. The highest mean scores of self-efficacy response is (3.25) and the lowest mean scores (1.91) was responded by students with high academic achievers (above 3.50 CGPA) and lower mean score responded by low academic achievers (below 2.00) respectively.

The results of self-efficacy responses showed a relationship with academic performances of the students. However, a few mismatches between self-efficacy responses and academic performances were observed among students' with 2.51 to 3.00 and 3.01 to 3.50 CGPA (in that; 2.784 mean score among students with 3.01 to 3.50 CGPA and 2.808 mean score among students with 2.51 to 3.00 CGPA).

In general it is held that self-efficacy has a positive relation on academic performance. The result of present study provides additional support for the often-observed positive relationship between self-efficacy and the academic achievement of students except with a few discrepancies. The findings of the present study revealed that there is a positive relationship between self-efficacy and academic achievement. The result of the present study is corroborated with the findings of the study conducted by (Hassen \& Sahravard, Yazachew, 2012; Talluri, 2018; Yokoyama, 2019), where they found a significant positive relationship between self-efficacy and academic performance of college students. The result of the study also indicated that there is a significant difference in the academic achievement of low selfefficacy students. Students with low self-efficacy scored low academic performance than students with high self-efficacy. 
Table 5: Pearson Correlation Results between Self-efficacy and CGPA of the Respondents

\begin{tabular}{c|c|c}
\hline Factor & \multicolumn{2}{c}{ Self-efficacy } \\
\hline \multirow{2}{*}{ CGPA } & Correlation & $.539^{* *}$ \\
& $\mathrm{~N}$ & 241 \\
\hline
\end{tabular}

As stated by Field (2009) and (Kothari, 2004), correlation is a standard statistical measurement of the degree of relationship or association between two sets of variables to describe how they are related to one another. If there were a relationship between the two variables, then as one variable deviates from its mean, the other variable should deviate from its mean in the same or directly in opposite way. Thus:

Self-efficacy was positively correlated with academic achievement: According to the data of table 5; Pearson's correlation coefficient, there was a positive relationship between selfefficacy and academic achievement $(r=.539)$. It was found that when students possessed high self-efficacy, they were more likely an increase in academic achievement. The finding of this study was also the same with similar study done in college of Ethiopia (Yazachew and Jibril, 2012; Talluri, 2018).

To sum up, self-efficacy was found or presented in the college on the shoulder of second year students in Robe College of Teachers Education, but the students guidance and counseling office was not presented to intervene the low self-efficacy difficulty of the students.

\subsubsection{Gender Differences in Self efficacy between Male and Female Students}

Table 6: Self-efficacy and CGPA by Sex of the respondents

\begin{tabular}{c|lllllll}
\hline \multirow{2}{*}{ Factors } & Sex & N & Mean & SD & \multicolumn{3}{c}{ All respondents } \\
\cline { 6 - 8 } Self-efficacy & Male & 88 & 2.68 & .594 & 241 & 2.46 & .636 \\
& Female & 153 & 2.33 & .625 & & & \\
\hline \multirow{2}{*}{ CGPA } & Male & 88 & 2.95 & 1.124 & 241 & 2.46 & 1.016 \\
& Female & 153 & 2.18 & .831 & & & \\
\hline
\end{tabular}

As shown in table 6, self-efficacy mean score for male students $(\mathrm{M}=2.68, \mathrm{SD}=0.59)$ and for female students $(\mathrm{M}=2.33, \mathrm{SD}=0.63)$ showed modest differences between male and female students reports for items associated with self-efficacy. Regarding academic achievements (CGPA), the differences were observed between male and female students' responses. The mean score for male students $(\mathrm{M}=2.95, \mathrm{SD}=1.12)$ was showed higher level of male students' academic achievements than female students $(\mathrm{M}=2.18 . \mathrm{SD}=0.83)$. However, highest standard deviation result $(\mathrm{SD}=1.12)$ for male students responses indicated the presence of greater divergences among male students academic performances (CGPA) than that of female students'. These data demonstrated that, female students' academic achievement was more affected by the self-efficacy than male students in the college. 
Table 7: Self-efficacy and CGPA: t-test results by sex of the respondents $(\mathrm{N}=241)$

\begin{tabular}{|c|c|c|c|c|c|c|c|c|c|}
\hline \multirow{3}{*}{ Variables } & \multicolumn{2}{|c|}{$\begin{array}{l}\text { Levene's Test } \\
\text { for Equality } \\
\text { of Variances }\end{array}$} & \multicolumn{7}{|c|}{ t-test for Equality of Means (2-tailed) } \\
\hline & \multirow{2}{*}{$\mathrm{F}$} & \multirow{2}{*}{ Sig. } & \multirow[t]{2}{*}{$\mathrm{T}$} & \multirow[t]{2}{*}{ Df } & \multirow{2}{*}{ Sig. } & \multirow{2}{*}{$\begin{array}{l}\text { Mean } \\
\text { Diff. }\end{array}$} & \multirow{2}{*}{$\begin{array}{l}\text { Std. } \\
\text { Error } \\
\text { Diff. }\end{array}$} & \multicolumn{2}{|c|}{$\begin{array}{l}95 \% \text { Confidence } \\
\text { Interval of Diff. }\end{array}$} \\
\hline & & & & & & & & Lower & Upper \\
\hline \multirow[t]{2}{*}{$\begin{array}{c}\text { Self- } \\
\text { efficacy }\end{array}$} & \multirow[t]{2}{*}{2.24} & \multirow[t]{2}{*}{0.14} & 4.26 & 239.00 & 0.00 & 0.35 & 0.08 & 0.19 & 0.51 \\
\hline & & & 4.31 & 189.24 & 0.00 & 0.35 & 0.08 & 0.19 & 0.51 \\
\hline \multirow{2}{*}{ CGPA } & \multirow[t]{2}{*}{11.48} & \multirow[t]{2}{*}{0.00} & 6.09 & 239.00 & 0.00 & 0.77 & 0.13 & 0.52 & 1.02 \\
\hline & & & 5.62 & 142.26 & 0.00 & 0.77 & 0.14 & 0.50 & 1.04 \\
\hline
\end{tabular}

* t-test is significant at the 0.05 level (2-tailed); the table value at the 0.05 level is 1.960 , and at the 0.01 level is 2.576

The differences observed between male and female students reports on self-efficacy; the result of table 6 and 7 indicated that, the mean scores for male $(\mathrm{M}=2.68, \mathrm{SD}=0.59)$; for female $(\mathrm{M}=2.33, \mathrm{SD}=0.63)$; and the calculated value of $\mathrm{t}$-test $(\mathrm{t}=4.26, \mathrm{p}<0.05)$ indicated statistically the presence of significant differences observed between male and female students of the college.

In relation to academic achievements (CGPA) the mean scores for male students $(\mathrm{M}=2.95$, $\mathrm{SD}=1.12)$; for female students $(\mathrm{M}=2.18, \mathrm{SD}=0.83)$; and the calculated $\mathrm{t}$-test value $(\mathrm{t}=6.09$, $\mathrm{p}<0.05)$ reviled that, statistically there was significant differences between male and female students. These data showed that, male students were much better than that of female students in their academic achievements in the college.

According to the overall data illustrated in table 7, the mean differences of each factor, significantly higher differences between male and female students were observed concerning their academic achievements (0.77). Moreover, a self-efficacy difference was observed between male and female students' responses were identified (mean differences 0.35).

In general, pertaining low self-efficacy was influencing academic performance of students; result indicated that, statistically there were significant differences between male and female students of the college. Significantly female students were lower in self-efficacy than male students. Besides, female students were more affected by self-efficacy during their academic life in the college. The finding of this study was also the same with similar study done in Albania (Shkullaku, 2013; Recber, Isiksal \& Koc, 2018; Talluri, 2018).

On the other hand the outcome of the statistical analysis both the descriptive, mean scores and independent sample t-test, results showed that the male participants were significantly different in their academic self-efficacy from the females who were participated in the study. The current study result also is consistent with the research works of (Yazachew and Jibril, 2012; Recber, Isiksal \& Koc,2018); whose works found gender differences in the students self-efficacy which implied male students to posses' better academic achievements than female students. This may happen due to the similarity of cultures where the studies took place. For instance, the Ethiopian culture specially, in the way we grow up our children and of the Eastern is almost similar, being in a culture where male is a dominant sex. 
Generally, the results of the present study revealed that there is a positive relationship between self-efficacy and academic achievement which is similar study conducted by (WittRose, 2003; Hassen \& Sahravard and Yazachew, 2012; Shkullaku, 2013; Talluri, 2018; Yokoyama, 2019).

\section{Conclusions}

The purpose of this research was to assess the relationship between self-efficacy and academic achievement. Accordingly, in academic performance, more than half of the respondents were scored low grades. The finding also showed students` with low self-efficacy were scored low grades. On the contrary, students`with high self-efficacy were scored high grades. More than half of the students were scored low and border achievers. This was due to selection problem while recruiting, low achievers were selected. The absence of guidance and counseling services also affected students' self-efficacy.

Regarding the status, more than half of the students were under low self-efficacy which low self-belief towards themselves. The result of students' positive responses for self-efficacy items was increased with an increase of students' academic achievements. From the finding, more than half of the students' were under low self-efficacy status.

The overall result of students' positive responses for self-efficacy items was increased with a rise of students' academic achievements and low achiever students' had low self-efficacy towards themselves. So, more than half of the respondents in Robe College of Teachers Education were under low self-efficacy. This may be resulted due to absence of training for students and life skills with due attention for low achievers and female students.

Self-efficacy was significantly and positively correlated with academic achievement. It was revealed that the relationship between self-efficacy and academic performance of college students. There were also significant differences observed between students in their academic performance. Students with low self-efficacy have been scored lower grades than students with higher self-efficacy. The result of current study revealed gaps observed between selfefficacy and the academic achievement among Robe College students.

Concerning gender differences, there was a difference in self-efficacy between male and female students. However, female students were more affected by self-efficacy than male students. In addition, greater differences were also reflected between male and female students' in academic achievement (CGPA). Male students were scored high academic performance than female students. Moreover, from t-test, male students were significantly higher in self-efficacy than female students. This refers that female students were more affected by self-efficacy than male students in college. This may happen due to the similarity of cultures where the studies took place. For instance, the Ethiopian culture specially, in the way we grow up our children in a culture is where male is a dominant sex.

\section{Recommendations}

On the basis of the findings and conclusions of current study, the following recommendations were forwarded: 
In order to rationally manage students' low self-efficacy among second year students; it is advisable if the Robe College of Teachers Education providing preliminary training for candidates, Oromia Educational Bureau and College should have to recruiting high academic achievers, establishing guidance \& counseling services, preparing on-the-job trainings on continuous bases on life skills, and by giving due attention for gender unit were forwarded. Moreover, it is suggested that future studies may consider interviewing some of the participants about reasons of low self- efficacy, other psychological variables and streams differences.

At the end, the study may uncover some of the causes of individuals' self-beliefs, selfregulation and self-perception. Another future research question could be if the relation among these variables and academic performance is moderated by gender unit, guidance and counseling would prepare training on psychological variables it will be better.

\section{References}

Akomolafe, M., G. (2013). The Role of Academic Self-Efficacy, Academic Motivation and Academic Self Concept in Predicting Students' Academic Performance: Journal of Education of Social Research, 3 (2), 2239-9780.

Bandura, A. (1997). Self-efficacy: The exercise of control. New York: W.H. Freeman and Company.

Borich,G. D. (1988). Effective Teaching Methods: University of Texas. NewYork: Macmillan Pub.Comp.

Chen, J. (2007). How the Academic support of parents, teachers and peers contribute to a student's achievement: New York: The Edwin Mellen Press.

Ching,H., Wang, Y. \& Liu, W.(2020). Exploring the Related Factors in Students' Academic Achievement for the Sustainable Education of Rural Areas: University Road, Taiwan; d10223002@yuntech.edu.tw.

Elias, S.M., \& Loomis, R.J. (2000). Using an academic self-efficacy scale to address university major persistence: Journal of College Student Development. 41(4), 450-454.

Federal Educational Policy, (1999). Educational Policy of Ethiopian Gov`t. Unpublished.

Feltz, D., Short, S., and Sullivan, P. (2007). Self-efficacy in sport-research and strategies for working with athletes, teams, and coaches. United States: Human Kenetics.

Ferla, J., Valcke, M, \& Cai, Y.(2009). Academic self-efficacy and academic self-concept. Learning and Individual Differences: Journal of Educational Science, 12 (9), 99-505. doi:10.1016/j.lindif.2009.05.004

Field, A. (2009). Discovering Statistics Using SPSS. London: SAGE Publications Ltd

Goulao, F. (2014). The Relationship between Self-Efficacy and Academic Achievement in Adults' Learners: Athens Journal of Education, 1(3), 237-246.

Hassen,S.A., \& Sahranavard, M. (2012). The relationship between self-concept, self-efficacy, selfesteem, anxiety and science performance among Iranian students. Journal of Scientific Research, 12 (9), 1190-1196.

Jeffreys, M. R. (1998). Predicting non-traditional student retention and academic achievement. Journal of Nurse Educator, 23(1), 42-48.

Jibril, J. (2012). Assessing major adjustment problems of freshman students in Jimma university: Ethiopian Journal of Education and Science, 7 (2), 1-14.

Koseoglu, Y, (2015). Self-Efficacy and Academic Achievement: A Case From Turkey: Journal of Education and Practice, 29(6), 2222-1735.

Kothari, C. R.(2004). Research methodology, methods and techniques. New Age International (2 ${ }^{\text {nd }}$ ed. ). India, New Delhi.

Kpolovie, J. (2014). Academic Achievement Prediction: Role of Interest in Learning and Attitude towards School, International Journal of Humanities Social Sciences and Education, 1(11), 73-100

Krejcie.R.V, \& Morgan. D.W., (1970). Determining sample size for research activities. University of Minnesota, Duluth Texas A. and M. University 
Lampert, J. N. (2007).The Relationship of Self-efficacy and Self-concept to Academic Performance in a College Sanlple. Testing competing models and measures: Thesis submitted to School of professional psychology, Pacific university

Lilian. K. (2012). A study of the Attitude, Self-efficacy, Effort and Academic Achievement. Students towards research methods and statistics: Journal of Scientific Research, 154(1), 154-183.

Oromia Education Bureau (August, 2017/8). A Guideline for Selection of Diploma (10+3) level teachers in Pre-service training Program. Finfinne: Teachers Development Panel.

Oromia Regional State (2013). Charter of Oromian Regional State Colleges. Finfinnee: Teachers Rules and Regulation.

Oyuga, A., Raburu, A., \& Aloka, O. (2019).Relationship between Self-efficacy and Academic Performance among Orphaned Secondary School Students in Kenya: International Journal of Psychology and Behavioral Sciences, 9(3): 39-46, doi: 10.5923/j.ijpbs.20190903.02

Recber, S., Isiksal, R. \& Koç, Y.(2018). Investigating self-efficacy, anxiety, attitudes and mathematics achievement regarding gender and school type: (http://revistas.um.es/analesps): 1695-2294, ISSN print edition: 0212-9728.

Sadler, M. and Sadler, D., (1999). Teachers, Schools and Society. New York: Mc Crai Hill, Company Press.

Schunk, D. H. (1984). Self-efficacy perspective on achievement behavior. Educational Psychologist, 19 (4), 48-58.

Shkullaku. R. (2013). The Relationship between Self - efficacy and Academic Performance. In the Context of Gender among Albanian Students: Journal of Academic Research, 4(1), 2286-4822.

Thuen, M, (2007). Learning environment, students' coping styles and emotional and behavioral problems. A study of Norwegian secondary school students, Dissertation for the degree doctor philosophiae University of Bergen. Norway

Talluri, S. (2018). Self-efficacy of secondary school students in relation to their gender and type of management; International Journal of Research and Analytical Reviews, Acharya Nagarjuna University, 5(3), 2349-5138

Usta, G, (2017). Examination of the Relationship between TEOG Score, Transition from Basic to Secondary Education, Journal of Education and Practice, 8(6), 2222-1735.

Witt-Rose (2003). Student self-efficacy in college science: An investigation of gender, age, and academic achievement.

Yazachew, A. (2012). Relationship between self-efficacy and academic achievement. Dabra Markos: Journal of Educational Psychologist, 3 (1), 2227-5835.

Yokoyama, S. (2019). Academic Self-Efficacy and Academic Performance in Online Learning: https://www.frontiersin.org/journals/psychology, doi.org/10.3389/fpsyg.2018.02794

Ysseldyke, J., \& Algozzine, B. (1995). Special Education. A Practical Guide for Teachers`. New Delhi: Houghton Mifflin Company.

Yusuf, M. (2011). The impact of self-efficacy, achievement motivation, and self-regulated learning strategies on students' academic achievement, Social and Behavioral Sciences, Universiti of Pendidikan, Malaysia.

Yusuf, O. A. (1998). Counseling Service in Institutions of Higher Education. Addis Ababa University, Addis Ababa. 